\title{
SUBJETIVACIÓN EN LA ESPUMA. ENTRE LA DISOLUCIÓN DE LA DIALÉCTICA INMUNOLÓGICA Y LA PRODUCCIÓN TÉCNICA DE LA INMUNIDAD Y EL SUJETO ${ }^{1}$
}

\author{
Marcelo Navarro Morales \\ Universidad Austral de Chile \\ marcelo.navarro@alumnos.uach.cl
}

\begin{abstract}
RESUMEN / ABSTRACT
En este trabajo analizo el surgimiento de las nuevas tecnologías de subjetivación farmacopornográficas (Preciado 2008) como productos de un cambio en los esquemas de organización y resistencia inmunológica experimentados en los cuerpos sociales desde mediados del siglo XX, y que supone la neutralización técnica de la otredad inmunológicamente efectiva (Han 2012) paralelo al desmoronamiento de la estructura y la semántica social dada la conformación de las espumas individualistas (Sloterdijk 2006). Para ello, analizo los efectos somatopolíticos de un corpus representativo de dichas tecnologías de subjetivación: la Píldora Anticonceptiva, el Viagra y PReP.
\end{abstract}

PALABRAS CLAVE: mal, tecnologías de subjetivación, profilaxis, régimen farmacopornográfico, espuma.

\section{SUBJECTIVISATION IN THE FOAM. BETWEEN THE DISSOLUTION OF THE IMMUNOLOGICAL DIALECTIC AND THE TECHNIC PRODUCCTION OF THE INMUNITY AND THE SUBJECT}

In this paper I analized the emergence of the new subjectivisation technologies pharmacopornographic (Preciado, 2008) as a result of a change in organizational schemes and immuneresistance experimented by the social bodies sincemid of the XX century, and involving the technical neutralization of other nessinmunolically efective (Han 2012) parallel to collapse of the semantics and social estructure because of the conformation of individualistic foams (Sloterdijk 2006). To do this, I analyze the somatopolitcs effect of an representative corpus of such subjectification technologies: the Pill, Viagra and PReP.

KEYWORDS: Evil, Subjectification technologies, Pharmacopornographic regime, Foam.

Este trabajo corresponde a un capítulo de mi tesis en curso para optar al grado de Magíster en Literatura Hispanoamericana Contemporánea, en la Universidad Austral de Chile, siendo Becario CONICYT-PCHA, Magíster Nacional 2015. 


\section{Introducción}

Yo es otro.

Arthur Rimbaud, Cartas del vidente.

El acto más sublime consiste en colocar otro delante de ti. William Blake, El matrimonio del cielo y el infierno.

RR Resultan de una enorme pluralidad los epítetos y calificaciones que ha recibido, todas las palabras que han sido erigidas en su nombre para trazar, si quiera, el perfil de su rostro y así explicar, a la manera de un indicio irrefutable de la veracidad de los dichos, las razones de la vacuidad de nuestras existencias ancladas a sus derroteros. Como el desdibujamiento de las diferencias entre los fonemas de una palabra repetida hasta el hartazgo, incesantemente, filósofos de las más variadas tradiciones y procedencias han dedicado incontables palabras a la cuestión de la relación entre subjetividad y tecnología. En este trabajo analizo el surgimiento de las nuevas tecnologías de subjetivación farmacopornográficas (Preciado 2008) como productos de un cambio en los esquemas de organización y resistencia inmunológica experimentado en los cuerpos sociales desde mediados del siglo XX, y que supone la neutralización técnica de la otredad inmunológicamente efectiva (Han 2012) paralelo al desmoronamiento de la estructura y la semántica social dada la conformación de las espumas individualistas (Sloterdijk 2006). Para ello, analizo los efectos somatopolíticos de un corpus representativo de dichas tecnologías de subjetivación: la Píldora Anticonceptiva, el Viagra y PReP, las cuales constituirían medidas institucionales profilácticas de exorcización de una dimensión corporal negativa o patológica. En términos generales pretendo confeccionar un mosaico que integre una variedad de perspectivas que nos permitan establecer una mirada panorámica acerca de nuestras tecnologías de subjetivación, de la influencia que estas tienen en la producción de un sujeto de acción y enunciación, con la finalidad de dilucidar las lógicas que nutren su funcionamiento, el modo en que operan y los desequilibrios políticos que provocan.

\section{Profilaxis en la espuma}

El antídoto del aburrimiento es el miedo. Emil Cioran, Del inconveniente de haber nacido.

En el primer tomo de La historia de la sexualidad (2009), específicamente en su último capítulo "Derecho de muerte y poder sobre la vida", Foucault sugiere la existencia de un proceso de reconversión de las dinámicas del poder en el siglo XVIII, desde una sociedad definida por el derecho soberano de captación de las cosas, los cuerpos y la vida; a una sociedad orientada a distribuir lo viviente en un dominio de valor y utilidad, que califica, mide, aprecia y jerarquiza a través de mecanismos continuos, reguladores 
y correctivos que invaden el espacio entero de la existencia. Esta transición estaría dada como el efecto de un conjunto de tecnologías de poder centradas en la vida, un biopoder concentrado en el aseguramiento, mantención y desarrollo de las vidas humanas, indispensables para el proceso de consolidación del capitalismo. Este último requirió la inserción controlada de los cuerpos en el aparato de producción y el aumento de las fuerzas, aptitudes y de la vida en general, por medio de técnicas de maximización lo suficiente diversas y numerosas para posibilitar la sujeción de los cuerpos y el control de las poblaciones; incidiendo, de este modo, en la fuerza de unos y otros, garantizando relaciones de dominación y efectos de hegemonía al insertar la vida en el campo de las técnicas políticas. El gobierno de lo vivo supuso, ante todo, lo que en Vigilar y Castigar (2003) Foucault describió como la puesta en marcha de una microfísica del poder, encargada de la ordenación de las multiplicidades humanas por medio de un control minucioso, disciplinario, de las operaciones del cuerpo; estableciendo con este último una relación de utilidad-docilidad producida por medio de tecnologías externas orto-arquitectónicas de encierro (látigos, cinturones de castidad, sanatorios, cárceles, etc.), que aseguran el funcionamiento automático del poder. De este modo, la disciplina inventa una anatomía política que funciona como una fábrica de cuerpos dóciles, es decir, cuerpos abiertos y susceptibles a una sujeción (assujetissement) subjetivadora a partir de la cual los cuerpos devienen sujetos de derecho. En esta mecánica del poder se encontraría el sexo en una posición central; no en el sentido de la instalación de una prohibición del sexo, sino que en el de su reglamentación mediante discursos útiles y públicos. Así, durante el transcurso del siglo XVIII, el arte de las sensaciones insoportables, cuyo foco se encuentra en el cuerpo, es progresivamente sustituido por la aplicación de una economía de los derechos suspendidos, cuyo foco se encuentra en el alma, es decir, en el control, neutralización y modificación de las disposiciones ontológicamente delictuosas del individuo.

Este carácter fundamentalmente bio-político de las tecnologías de gestión de la vida tiende a sustraerse en una discursividad regida por principios y códigos que sustentan su legitimidad, el grado cero de su ideología, siendo demandada e investida públicamente como criterio para la evaluación del desarrollo y crecimiento de las naciones. Evidentemente este nuevo enfoque, que viene a romper la lógica soberana y a instalar el problema del gobierno de los otros, de las técnicas de gobierno, de la gubernamentalidad del ser vivo, ha conseguido inimpugnables beneficios: el considerable aumento de la esperanza de vida es quizás uno de los efectos de mayor alcance de la transición histórica de la sociedad soberanía a la sociedad disciplinaria; en tanto que, en términos generales, la experiencia vital de los sujetos del lado occidental del mundo se encuentra notoriamente influida y mediada por la institucionalidad médica y la industria farmacéutica. Sin embargo, ¿cómo entender, por ejemplo, el fenómeno de la bomba atómica, la amenaza de la exposición de poblaciones enteras a una muerte general e instantánea, en un espacio social cuyo objetivo y expectativas institucionales están puestas en la maximización y preservación de la vida? ¿Qué lógicas implícitas se sustraen en los derroteros de la investigación científica al posibilitar la coexistencia de proyectos de naturaleza tan disímil, como lo son la clonación y la producción de armas de destrucción masiva? 
"Si la explosión de las dos primeras bombas atómicas en Hiroshima y Nagasaki, en 1945, señala el principio de un apocalipsis geopolítico, la aparición de Dolly, la primera oveja clonada, señala el principio de un apocalipsis biológico" (Preciado 2008: 161). Con estas palabras, Preciado señala dos momentos decisivos de la historia reciente que demarcan la trayectoria del desarrollo de la tecnociencia desde mediado del siglo XX. A partir del carácter inédito de las modalidades y la potencia con que se ejerce esta doble cara, necro-bio-política, conseguimos afirmar una sospecha categórica: hemos dejado atrás la época de una orto-arquitectura transparente a la gestión poder, de tecnologías disciplinarias-externas-duras que develan, en sus rústicos mecanismos adosados a la materialidad de los cuerpos, la relación entre la vida y el poder; para pasar a una época donde las técnicas de gobierno de lo vivo se complejizan, no para el descubrimiento de una verdad útil a la humanidad, sino que para tornarse una ciencia de los extremos en busca de resultados límites (Virilio 1999). A partir de la aparente incongruencia entre las lógicas que distancian y dan vida a ambos proyectos -la bomba atómica y la clonación-, cada uno instalado en los extremos opuestos de una misma recta, podemos afirmar que la época en que vivimos es, por lo menos, diametralmente distinta a la sociedad disciplinaria estudiada y descrita ampliamente por Foucault. Esta transición, sin embargo, no estaría dada por una reconversión de las dinámicas del poder, de un poder soberano a un bio-poder, sino que más bien por una radical sofisticación de las tecnologías que posibilitan el ejercicio fáctico de gestión de las formas de vida, desde la capacidad automática de deshacer el cuerpo biológico a la capacidad de producirlo artificialmente.

Preciado (2008) identifica los hitos que delatan este cambio en las modalidades de la gestión biopolítica durante el siglo XX: la millonaria inversión en investigación científica en sexo y sexualidad, la puesta en marcha de la utilización clínica de moléculas hormonales, la concepción del término "género", la invención de la primera píldora anticonceptiva, la producción de elementos transuránicos como combustible nuclear, el desarrollo de la cirugía estética, la generalización del uso del plástico en la fabricación de objetos de la vida cotidiana, la transformación ecológica del mundo a gran escala como producto de la destrucción de los recursos energéticos primitivos del planeta, la creación de la primera revista pornográfica norteamericana Playboy, la invención de los primeros antidepresores, la creación de la primera red de computadores interconectados capaces de trasmitir información, Arpanet, la instalación de regulaciones institucionales en el consumo y tráfico de sustancias psicotrópicas que excluyen de la prohibición el alcohol y el tabaco, el desarrollo de múltiples tecnologías moleculares y prostéticas para el tratamiento de la disfunción eréctil, la realización de Garganta profunda y el estallido de las producciones cinematográficas porno, la sintetización y aprobación del uso de Sildenafil más conocido como Viagra. Todos estos eventos ocurren aproximadamente en un período comprendido entre el fin de la II Guerra Mundial, en 1945, y la caída del Muro de Berlín, en 1989, es decir el período histórico en que tendría lugar la Guerra Fría que culminaría con la victoria definitiva del capitalismo democrático frente a las ideologías totalitarias; pero también, asimismo, el período de decaimiento y crisis del proyecto moderno humanista que se propone transparentar el mundo por medio de la razón y la palabra. 
Cada uno de estos eventos se enmarcan en el desarrollo de un tercer momento del capitalismo, ahora, postindustrial que trasciende o sobrepasa la producción en cadenas de montaje, los motores de combustión y la utilización de fuentes energéticas como el gas, el petróleo y la electricidad que, indiscutiblemente, revolucionaron los transportes y la calidad de vida de las personas en el siglo XIX; cambiando el modelo de acumulación primitiva, de la privatización de los medios de producción industrial, a una suerte de privatización o acumulación de capital inmaterial: el proceso productivo en la época postindustrial tiene como materias primas el saber, la información, la cultura y las relaciones sociales, donde el lenguaje se presenta como un terreno de conflicto y como aquello que se encuentra en juego, en tanto que nuestra época ha puesto a trabajar los lenguajes mismos (Virno 2003) en función de lo que podríamos denominar, haciendo uso de las palabras de Hardt y Negri (2000), como una colonización informacional del ser. Siguiendo a Burroughs y ampliando las ideas de Foucault acerca de la sociedad disciplinaria, Deleuze denominó este nuevo momento del capitalismo como sociedad de control, la cual estaría caracterizada por la abolición relativa de los antiguos espacios de encierro y la instauración de disposiciones que otorgan a los sujetos una aparente libertad en condiciones de perfecto control, abierto y continuo: "mediante una autopista no se encierra a nadie, pero se multiplican los medios de control. No digo que éste sea el único fin de la autopista, sino que la gente pueda entrar y salir infinita y libremente de ellas sin estar en absoluto encerrada pero estando perfectamente controlada" (Deleuze 2008: 288). La información es decisiva en el contexto de las nuevas condiciones sociopolíticas, en tanto que esta emana del sistema de control que hace circular un conjunto de consignas, de órdenes, acerca de lo que se "supone que somos de hecho o lo que debemos ser o lo que estamos compelidos a creer. No se nos pide que creamos, sino que nos comportemos como si creyéramos. Esto es la información, la comunicación, y no hay información alguna al margen de estas consignas y de su transmisión" (2008: 287).

Por medio de una libertad condicionada a la capacidad adquisitiva de los consumidores, la sociedad de control sustrae los límites de las libertades individuales tras consignas difundidas por la publicidad y los medios que legitiman y actualizan los mitos que alimentan su funcionamiento. Para Deleuze, en Postdata sobre las sociedades de control (1991), el dinero y las máquinas develan la profunda mutación del capitalismo: la moneda acuñada contenedora del patrón oro, dio paso a una economía de intercambios fluctuantes, de modulaciones ondulatorias; así como las máquinas simples, con palancas, poleas y engranajes, fueron sustituidas, primero, por máquinas energéticas y, luego, en nuestra historia más reciente, por máquinas informáticas y ordenadores, por la química farmacéutica, la edición genética y los medios de comunicación masivos. Estas últimas son tecnologías cuyos usuarios asumen como constitutivas de un principio democrático de libertad, en condiciones que son el medio a través del cual el poder permea a los sujetos, dictaminando la organización de las mentes, suscritas determinadas redes de información, y los cuerpos, sujetos a suplementos farmacológicos, absortos en sistemas de bienestar y actividades recreativas monitoreadas, gestionando, de esta forma, nuestras prácticas comunes y cotidianas, induciendo un estado de alienación autónomo y voluntario acerca del sentido de nuestras existencias (Hardt y Negri 2000). De este 
modo, la sociedad de control esconde sus mecanismos coactivos tras la aparente libertad del individuo que, sin ser disciplinado por el látigo o sometido al mandato irrecusable de sus superiores jerárquicos, opta por el imperativo paradójico sé libre, es decir, por la auto-explotación voluntaria y libre que precipita a este empresario de sí mismo a la depresión y el agotamiento (Han 2014). La enfermedad por la polifarmacia, la fábrica por la empresa, el encierro por la deuda, la disciplina por el marketing: en esto pareciera consistir el acuerdo tácito entre las subjetividades y las tecnologías de gobierno de lo vivo durante los últimos 70 años.

Sin embargo, habría que realizar algunas observaciones respecto a los juicios expuestos hasta el momento. Deleuze, en su tardío intento por abordar las cuestiones aquí anteriormente señaladas, omite que esta transición histórica está marcada por un cambio en los esquemas de organización y resistencia inmunológica, por un paulatino proceso de exorcización del Mal en la vida política y social en las comunidades humanas. El modelo inmunológico es una condición que pertenece a alguien (yo, lo interior, lo propio, lo individual), e impide que otra fuerza se manifieste (lo otro, lo exterior, lo extraño, lo común) por medio de la negación, es decir, con ayuda de un "no" que posibilita la producción de fronteras simbólicas que sirven a la identificación de lo propio y lo extraño, del interior y lo exterior, de lo individual y lo común (Esposito 2006). El paradigma inmunológico, en los términos generales recién señalados, forma parte de la experiencia vital de los grupos humanos en general y de la experiencia histórica de las naciones: “¿Qué es y ha sido siempre la historia universal, sino historia, también, de guerras entre sistemas de inmunidad?” (Sloterdijk 2003: 68). Ineludiblemente, las lógicas que animaban estos mecanismos inmunológicos han sido radicalmente transformadas durante la historia reciente, viendo sus otrora lánguidas tentativas locales, fuertemente resistidas, cristalizadas ahora en el afianzamiento de la globalización en los $90 \mathrm{y}$, todavía más, en el inicio del nuevo siglo: la reciente visita de Barack Obama a Cuba, Argentina e Hiroshima, antiguos reductos de resistencia contra el capitalismo, marca la victoria (quizás) definitiva del nuevo paradigma global. Resulta conocida la hipótesis de Francis Fukuyama, de que la finalización de los conflictos ideológicos, posterior a la Guerra Fría, y el triunfo de la democracia liberal, han provocado la entrada de la sociedad a una época posthistórica; o bien, en términos de Zizek (2008), postpolítica, en el sentido de que las viejas luchas ideológicas entre el capitalismo y el comunismo han dado paso a la administración política y económica de tecnócratas ilustrados y liberales multiculturalistas, que aseguran al cuerpo social que las reivindicaciones o quejas de los grupos sociales invisibilizados o marginales queden tan solo en fenómenos puntuales.

Byung-Chul Han, en La sociedad del cansancio (2012), explica que en nuestra sociedad habría una tendencia a la supresión de la otredad inmunológicamente efectiva, dada la incompatibilidad de la dialéctica negativa de la inmunidad con el proceso de globalización. En este sentido, la tolerancia liberal del capitalismo democrático está supeditada a la condición de que la presencia del otro "no sea invasiva, mientras ese otro no sea realmente otro" (Zizek 2009: 57), a la condición de la reducción de la otredad a la diferencia potencialmente consumible (Han 2014). Al respecto, Zizek se pregunta: “¿No es acaso la historia del capitalismo una larga historia de cómo el contexto ideológico-político dominante fue dando cabida (limando el potencial subversivo) a 
los movimientos y reivindicaciones que parecían amenazar su misma supervivencia?" (2008: 69). Guattari (2006), abocado al mismo problema, habla de la recuperación de los valores de singularidad, a través de un paulatino proceso de integración de lo singular y disruptivo al propio sistema cultural capitalista; dando como ejemplos de este fenómeno la universalización del jazz de los negros y el aseguramiento de derechos civiles a mujeres y homosexuales. Como consecuencia de este panorama, formamos parte de una sociedad pobre de negatividad pero que no ha conseguido librarse de la violencia ya que esta no se ejercería únicamente desde la otredad, sino que también de la sobreabundancia de lo idéntico, de un exceso de positividad, cuya violencia es la violencia de la disuasión, la neutralización, del control que emerge de la supresión de un dominio externo y que hace coincidir libertad y coacción (Han 2012). Por esta razón, para Han el término sociedad de control resulta inadecuado, ya que en su sintaxis designa demasiada negatividad en condiciones de que pretende designar una sociedad que, contrario a lo que pudiéramos pensar, se caracteriza por su positividad, por su carácter eminentemente productivo, subjetivador.

Para Baudrillard esta neutralización de la alteridad, del Mal, en tanto principio constitutivo de la dialéctica inmunológica, paralelo a un enfoque técnico del Bien, provocaría una metamorfosis del Mal, que, ahora, asumiría las formas víricas del SIDA, los virus informáticos, el crack bursátil, el terrorismo, la drogadicción, pero también la forma de la célula cancerígena y su inmortalidad patológica, ya que

toda estructura, todo sistema, todo cuerpo social que acosa, expulsa o exorciza sus elementos negativos y críticos, corre el riesgo de sufrir una catástrofe por reversión e implosión total, del mismo modo que todo cuerpo biológico corre el riesgo de padecer un cáncer, es decir una positividad devoradora de sus propias células, corre el riesgo de ser devorado por sus propios anticuerpos, ya sin empleo (2000: 11).

El Bien, el ideal de la felicidad integral, concebido de una manera proteccionista, emergería de la profilaxis del Mal, de su minimización, de su reducción a la cuestión de la evasión de la desgracia, a su carácter accidental y técnicamente revocable, que daría lugar a una redención general, a una reescritura definitiva de la mano de la técnica: el pasado histórico "será redimido, todo será rehabilitado, limpiado hasta la transparencia. En cuanto al futuro, la perspectiva resultará aún mejor y peor: todo se modificará genéticamente a fin de lograr la perfección biológica y democrática de la especie" (2008: 141, 142). La desaparición de la negatividad y de la alteridad, condición sine qua non de la experiencia erótica, es contiguo al surgimiento de un sujeto abocado exclusivamente al cuidado narcisístico de sí mismo que, sustraído en su depresión, condenado a aceptar su importancia, recluido en el infierno de lo igual, se halla absorto en su mismidad al considerar su propia existencia como fin absoluto y elevar la diversión a un motivo de vida (Sloterdijk 2006 y Han 2014). El sujeto individualista ha sucumbido bajo una ficción de autonomía:

Los particulares en el régimen individualista se convierten en sujetos puntuales que han caído en manos del poder del espejo, es decir, de la función reflectiva, autocompletante. Cada vez más organizan su vida bajo la ilusión de que podrían 
realizar, sin un otro real, el papel de las dos partes en el juego de relación en la esfera bipolar; esa ilusión se va concretando (...) hasta llegar a un punto en el que los individuos mismos se consideran definitivamente como lo primero sustancial, y sus relaciones con otros, como lo segundo accidental (Sloterdijk 2003: 192).

La abolición de la dialéctica inmunológica, explicada en los términos recién citados, descubre el motivo y la relevancia cobrada en el último tiempo respecto a la producción de una inmunidad artificial ortopédica, técnicamente suplementada, cuyo paroxismo se expresa en el proyecto de la clonación en tanto amalgama de lo propio y de lo ajeno, en tanto producción técnica de un yo vuelto otro. Esta producción artificial de la inmunidad termina por equiparar el proceso civilizatorio al desarrollo de la capacidad de adopción (institucional), a la protetización explícita de las funciones alomaternales, según la aspiración de otorgar a los ciudadanos un mimo integral cada vez más amplio en el invernadero de bienestar en que, parcialmente, se ha tornado y/o que aspira a tornarse el mundo entero (Sloterdijk 2006). De este modo, la lucha de clases deja de ser motor de la historia articulador de los movimientos sociales, para ser sustituida por la envidia al otro, en el sentido de que lo que moviliza al sujeto no es un proyecto político, con peso histórico e ideológico, sino que la sensación de que su individualidad en particular está siendo desatendida por el Estado de bienestar, dispuesto allí para democratizar el lujo: lo único que moviliza al sujeto es la tarea de sustraerse del peso histórico del mundo, por lo que, hundido en su pacífica levedad positivada, y con un amplio e inédito abanico de posibilidades existenciales a su disposición, oscila, en un estado de ánimo crónicamente ambivalente, entre el aburrimiento y el estrés (Sloterdijk 2010).

La supresión de la otredad inmunológicamente efectiva (Han 2012) en favor del cuidado de la mismidad (Sloterdijk 2006) es un fenómeno concatenado a la contaminación dromosférica de las distancias (Virilio 1997) que imposibilita la consumación del Eros en tanto acto voluntario de desreconocimiento de sí mismo (Han 2014). Con el término contaminación dromosférica, Virilio denomina el fenómeno de la desaparición de las distancias por medio de las tecnologías del tiempo real, las cuales disuelven la amplitud del medio humano en un medio virtual, haciendo desaparecer la realidad geofísica del cuerpo territorial del planeta y degradando, junto con esta, la proximidad física entre los seres: "misteriosamente, la ciencia de las máquinas nos exilia, tanto del mundo geofísico como del cuerpo físico del otro" (1997:150). Han, coincidiendo con esta postura, arguye que la pérdida de este distanciamiento, la eliminación total de la lejanía, implica la pérdida de la capacidad de experimentar al otro en su otredad: "intentamos hoy acercar al otro tanto como sea posible, destruir la distancia frente a él, para establecer la cercanía. Pero con ello no tenemos nada del otro, sino que más bien lo hacemos desaparecer" (2012:13). Para este autor, nuestro presente optimizado por la tecnología, positiva el amor como mera sexualidad abierta al consumo, carente de rostro y, por tanto, de alteridad. Así, de esta relación, sin otro ni distanciamiento, no puede emerger el amor ya que el sujeto "permanece igual a sí mismo y busca en el otro tan solo la confirmación del sí mismo" (2012: 18). De ahí que para Han, el porno sea la antípoda de la experiencia erótica y el fenómeno que caracteriza a nuestra sociedad de la transparencia en el sentido de que la "hipervisibilidad va unida con el desmontaje 
de umbrales y límites" (2014: 33), en este caso, al límite negativo del distanciamiento, neutralizado tecnológicamente, que condiciona la posibilidad de amar al otro.

Preciado, en Pornotopia (2010), estudia la mutación de la domesticidad suburbana a partir de la influencia ejercida por la revista Playboy (1953) en el diseño del hábitat arquitectónico idóneo para el cultivo del alma adscrita a este tercer momento del capitalismo. Para Preciado, con esta revista, Hugh Hefner inventa la pornografía moderna haciendo circular en la esfera pública, a través de los mass media, lo que hasta ese momento era considerado privado; dando inicio, de esta forma, a un proceso de transformación de las relaciones tradicionales entre género, sexo y arquitectura, a partir de la subjetivación, técnicamente mediada, de un nuevo consumidor masculino que -reivindicando su derecho a un espacio doméstico autónomo, específicamente masculino y no regido por las leyes sexuales y morales del matrimonio heterosexualviene a redefinir la rígida división de género en que se distribuía dicotómicamente el espacio social todavía en ese entonces, entre lo público-exterior-político-masculino y lo doméstico-interior-privado-femenino. Lo que Playboy realiza es la promoción de un modus vivendi que se propaga o contagia miméticamente a través de la población, y que, en definitiva, se reduce a la cuestión de la confección del paraíso íntimo, del voluntario confinamiento en la domesticidad perfecta, convertida en el observatorio definitivo al resguardo de los peligros del exterior atómico durante la postguerra. Sin lugar para el aburrimiento profundo benjaminiano, el sujeto representado en Playboy se abstrae de sí mismo en la pura agitación estéril.

Una cama grande, una fortaleza revestida de madera preciosa, paredes sin ventanas y un montón de aparatos electrónicos llenos de decenas de botones y teclas. Es la imagen de un aislamiento mullido, apacible y totalmente hedonista. El solitario dispone de todo aquello que reconoce como una necesidad, incluso la garantía de una fiesta permanente en el piso inferior en la que podrá ir a dar una vuelta si en algún momento lo roza el aburrimiento (Arcand 1993: 177).

La exhibición de la vida en la Mansión Playboy supondrá una radical transformación de la noción de privacidad: de pronto, las fronteras materiales que separan y diferencian el espacio público del privado se tornan alarmantemente porosas o bien se yuxtaponen; ya que el hogar, tradicionalmente privado, aparece convertido en una celda postdoméstica, nunca del todo privada, "en [la] que los habitantes son conscientes de su doble condición teatral, sirviendo al mismo tiempo como actores y espectadores" (2000: 85) de un reality show sin final aparente. A partir de Playboy, el crecimiento exponencial de la industria del entretenimiento para adultos se tornará un indicador de una tendencia más general de nuestra sociedad: arrancar de la vida la realidad sensible, sustituir el ser sustancial por su sombra (Virilio 1997). Así, el porno aspira a la sustitución del encuentro sexual y material entre los cuerpos, por la exhibición de la espectacularidad del sexo entre cuerpos perfectos, colándose la profilaxis del mal a través del deseo: la enfermedad de transmisión sexual por la masturbación telecomandada, la frágil protección del condón por el preservativo electromagnético. Playboy capitaliza un sueño masculino: acceder en todo momento, desde la comodidad de la celda postdoméstica, al placer sexual desprovisto del cuerpo del otro. 
La preeminencia de la masturbación telecomandada en el espacio de seguridad y el confort individualista coincide con una progresiva politización y mercantilización de dicho espacio, con una batalla semiótica y estética en torno a la información, la arquitectura y los objetos de consumo (Preciado 2000), que constituirá el principio de la mutación de las tecnologías de gestión biopolítica durante la segunda mitad del siglo XX. En Vigilar y Castigar, Foucault considera el Panóptico como una fórmula arquitectónica, como una máquina o técnica decisiva y característica de la sociedad disciplinaria, puesto que a través de ella es posible entrever y describir las lógicas que se sustraen en el ejercicio del control y de la vigilancia de los cuerpos. Preciado, por su parte, propone que Playboy, inversamente proporcional, podría ser considerado como el eje conductor entre la sociedad disciplinaria, desvelada a través de la arquitectura panóptica, hacia las nuevas formas de gestión biopolítica: el contenido de esta revista y sus múltiples extensiones y variables habrían abierto paso a la consolidación de lo que Sloterdijk convino en denominar la espumización de lo real.

Este último autor, sin embargo, rastrea bastante más atrás en el tiempo la génesis de las ideas que dan vida a Playboy y que esta a su vez masificó y llevó a su límite. La idea de la internación en espacios confortables y biológicamente seguros ya se perfilaba en los descubrimientos de Pasteur y Koch a finales del siglo XIX y principios del XX: la existencia de los microbios puesta al descubierto por estos científicos supuso que tendríamos que acostumbrarnos a medidas explícitas de simbiosis con lo invisible, con la prevención y defensa frente a los microbios, lo cual implicaría a largo plazo la derogación definitiva de la metafísica monológica que interpreta el mundo como monocontexto y lo proyecta a un solo ojo; puesto que la vida no estaría determinada por la participación en el todo, sino que por la clausura en sí misma, por el desarrollo de una ontología plural y disposiciones de seguridad biológica, que toman en cuenta tantos mundos como tipos de ojos y demás sensores hay para verlo y sentirlo (Sloterdijk 2006). Playboy es una proyección cultural que emerge como resultado de las figuraciones que ya se venían gestando mucho tiempo atrás y que, a su vez, emergen a partir de un proceso de neutronización social, es decir, de reducción del tejido social a sus partículas elementales: "hemos llegado al punto en el que todas las formas compuestas parecen ser susceptibles de deconstrucción, desintegramos hasta alcanzar el nivel del neutrón. Esto es válido tanto para la materia física como para las sociedades y los tejidos simbólicos, tanto para los textos como para los rituales" (Sloterdijk 2003:94). En términos materiales y arquitectónicos, este fenómeno se traduce en la proliferación de edificaciones de alturas, particularmente, en lo que conocemos como el apartamento moderno, máximo representante arquitectónico de las espumas, tan característico de las áreas metropolitanas: el individuo liberado de la paternidad, del trabajo físicamente agotador y convertido en un consumidor controlado dedicado al cuidado de las relaciones consigo mismo, reduce su hábitat a una egósfera atómica o elemental, a una burbuja celular amontonada una sobre otra que comparten entre sí un principio de coaislamiento de cuya repetición masiva surgen las espumas individualista (Sloterdijk 2006).

El fenómeno sociológico de la espuma es capaz de explicar tanto la profundización de las modalidades de gestión biopolítica de los cuerpos, ahora parcelados en microespacios de seguridad y confort creados a expensas de la capacidad de endeudamiento del propio 
sujeto a disciplinar, como, asimismo, la crisis de los relatos sociales que otorgaban sustento a los proyectos históricos, donde el sujeto que tomaba en sus manos el devenir de la historia como parte constitutiva de una colectividad, pasa a ser sustituido por el sujeto del Estado de bienestar que se concentra exclusivamente en el cuidado de sí. Si en este apartado analizamos el proceso de abolición de la dialéctica inmunológica en términos generales, ahora nos corresponde analizar este mismo proceso en la singularidad de los cuerpos, es decir, de qué manera opera la gestión biopolítica al interior de cada una de estas egósferas elementales. Para ello nos concentraremos en tres tecnologías específicas de subjetivación dispuestas al interior de la espuma y que tienen en común el carácter de constituir medidas profilácticas de positivación de los cuerpos.

\section{Profilaxis y subjetivación farmacopornográfica: de la Píldora, el Viagra y $\operatorname{PrEP}$}

El sexo ya no existe, lo ha reemplazado el miedo. Paul Virilio, La velocidad de liberación.

Para Sloterdijk, la metáfora de la espuma es decidora respecto de nuestra situación actual: atrás ha quedado la burbuja dual, el ser junto a otro, y el globo único integrador, político, centrado y omnicomprensivo, para dar paso a la espuma, es decir, a un espacio social poliesférico conformado por unidades frágiles en estrecha vecindad, pero donde la estructura y la semántica social se han desmoronado dada la cofragilidad y el coaislamiento de cada célula de espuma imbuida en sí misma (2006). Sin embargo, hemos hallado en el camino de la técnica, de la inmunidad artificialmente suplementada, la posibilidad de subsanar nuestras carencias, de llenar el vacío de aquello que hemos perdido durante la realización del proyecto fáustico de la modernidad.

La civilización altamente tecnológica, el Estado de Bienestar, el mercado mundial, la esfera de los media: todos esos grandes proyectos quieren imitar en una época descascarada la imaginaria seguridad de esferas que se ha vuelto imposible. Ahora, redes y pólizas de seguros han de ocupar el lugar de los caparazones celestes; la telecomunicación debe imitar lo envolvente. El cuerpo de la humanidad quiere procurarse un nuevo estado de inmunidad dentro de una piel electrónico-mediática. Puesto que lo omniabarcante y lo omnicomprensivo de antes, la bóveda continens celeste, se ha perdido irremediablemente, lo ya no abarcado, lo ya no comprendido, (...) tiene que procurarse ello mismo su bienestar en continentes artificiales bajo cúpulas y cielos artificiales (Sloterdijk 2003: 34).

Guattari y Rolnik en Micropolítica. Cartografías del deseo (2006) y Preciado en Testo Yonki (2008) se concentran, aunque desde trincheras distintas, en realizar una vivisección de esta piel electrónico-mediática de la cual hemos provisto nuestro mundo. Ambos autores parten de la base de que cada una de las células-habitáculos que componen la espuma social y nuestras individualidades desplegadas en dichos microespaciosindoor se encuentran atravesadas por un conjunto de tecnologías de subjetivación. Estas tecnologías emanarían de este nuevo régimen capitalista postindustrial, 
global, farmacológico y mediático que aquí denominaremos en términos generales como régimen farmacopornográfico. Este concepto propuesto por Preciado (2008), a diferencia de la noción de sociedad de control de Deleuze, resulta más idóneo para designar el surgimiento de esta nueva generación de técnicas de gobierno de lo vivo, dado que en la morfología de este concepto aparecen sintetizadas las dos tecnologías de subjetivación fundamentales dispuestas en el interior de las espumas sociales: la biomolecular (fármaco) por un lado y el semiótico-técnico (pornográfico), por otro, a través de los cuales tendría lugar la producción sociopolítica en serie de las subjetividades vueltas objetos de su poder y saber.

Sin realizar todavía distinción alguna, esta red de técnicas políticas constituye lo que Guattari (2006) denomina como tecnologías de subjetivación serializada, las cuales, en conjunto, conforman una gran fábrica capitalista de producción de subjetividades. Según esta perspectiva, la subjetividad resulta una cuestión de naturaleza industrial, registrada socialmente, maquínicamente ensamblada, moldeada según una relación de correspondencia entre el capital y los cuerpos, dado que estos últimos consumen sus sistemas de representación y de sensibilidad producidos por su sistema cultural, cuyos valores los sujetos deben interiorizar y con los cuales, inexorablemente, terminan por identificarse, oprimirse y alienarse, pasiva e involuntariamente. De este modo, el orden capitalista produce también los modos admitidos de relaciones humanas, ya que todo deseo, voluntad de amar o crear deben coincidir imperativamente con las referencias dominantes; de otro modo, cuando creamos territorios singulares, corremos el riesgo de ser marginalizados. De ahí que Guattari utilice el epíteto de serializado, en el sentido de que la producción capitalista de las subjetividades pasa a través de un proceso de normalización centrado en una imagen de consenso subjetivo que sirve de referente. En este sentido, el capitalismo funcionaría como un sistema de tecnologías positivas, productoras y reguladoras de una ontología psicosocial homogénea, al mismo tiempo que neutralizadoras (profilácticas) de la otredad singular y negativa.

Para Preciado (2008), la noción de género sería un condicionante en la formulación de estas técnicas fotográficas, biotecnológicas, quirúrgicas, farmacológicas, cinematográficas y cibernéticas que conforman, cada una, desde sus diferentes códigos, la materialidad de los sexos y los patrones conductuales. Para esta autora, el género y el sexo emergerían entonces como un efecto de este sistema de significación, del cruce de representaciones discursivas y visuales que proceden y se reproducen a través de diferentes dispositivos institucionales: la familia, la religión, la medicina, el sistema económico, educativo, judicial, los medios de comunicación, etc. Siguiendo a Lauretis, Preciado emprende el análisis de estas tecnologías de género, de tecnogénero, en tanto que se encuentran al servicio de la producción y reforzamiento de modelos identitarios estrechos y homogéneos, y respecto a los cuales los sujetos de acción y enunciación deben imperativamente identificarse para acceder a la inteligibilidad social y política. En definitiva, estas serían tecnologías de control biomediático de la subjetividad, tecnologías de producción de ficciones somatopolíticas normalizadoras, que combinan la síntesis y comercialización de moléculas de gestión y producción de los cuerpos sexuados, así como de técnicas de representación del género y la sexualidad (2008). 
Al nivel de los fenómenos corporales, es posible explicar el lugar central detentado por la medicina y sus subespecialidades clínicas y quirúrgicas de reciente invención vinculados con la imagen corporal (como lo son la nutriología o dietética y la cirugía plástica), como discursos que responden al interés masivo, suscitado en el último tiempo, en el cuidado de la mismidad. Sin embargo, al nivel de los fenómenos masivos de población, la creciente medicalización de los cuerpos es un fenómeno correlativo determinante en la instalación de las tecnologías de subjetivación, ya que es por medio de la intervención médica de las variables que determinan la salud de los cuerpos (desde el saneamiento del agua hasta las prácticas sexuales privadas) que esta se ha tornado un "poder autoritario con funciones normalizadoras que van más allá de la existencia de las enfermedades y de la demanda del enfermo" (Foucault 2016: 93). Recordando las propuestas de Foucault, la gestión biopolítica, sus tecnologías reguladoras, múltiples y continuas, evidentemente no se despliegan de manera uniforme en el cuerpo social, sino que, más bien, diferenciando los cuerpos de acuerdo a criterios de valor y utilidad. En este sentido, resulta lógico que las mujeres, dada su capacidad reproductiva, constituyan un objeto de particular interés para los médicos: de ahí la inexistencia de un equivalente masculino al ginecólogo, la profesionalización de la práctica obstétrica, la formulación de procedimientos seguros para el parto, la lucha contra el aborto, la producción de tratamientos farmacológicos para tratar o revertir la esterilidad, el perfeccionamiento del saber acerca de las hormonas femeninas; todos hitos científicos que tienen como objeto exclusivo de conocimiento a la mujer y que prefiguran las condiciones para la emergencia de la píldora anticonceptiva (Courtine 2006). Coincidiendo con Guattari y trascendiendo el conocido aforismo con que Simone de Beauvoir asienta las bases del postfeminismo, "No se nace mujer: llaga uno a serlo", Preciado propone que la feminidad, entendida de la manera en que la conocemos convencionalmente en occidente, no existiría sin un conjunto de técnicas mediáticas y biomoleculares que la construyen artificialmente: "Las bio-mujeres son artefactos industriales modernos, tecno-organismos de laboratorio" (2008:126).

Preciado ejemplifica el carácter maquínico de la subjetividad femenina, a través del análisis de los efectos somatopolíticos de la píldora anticonceptiva. Esta, más que una técnica de control de la reproducción, abierta al mercado en 1960, sería una técnica de producción y control del género: la píldora sería capaz de producir técnicamente los ritmos de los ciclos menstruales naturales por medio de una suerte de travestismo somático (bio-drag) donde el sangrado, técnicamente inducido, produce la ilusión del ciclo menstrual natural (2008). Tan solo a través de la sospecha de la existencia de intenciones encubiertas por la industria farmacéutica conseguimos explicar las razones de la increíble prioridad con que ha sido embestida la píldora anticonceptiva por parte de los discursos médicos y judiciales, en detrimento de métodos anticonceptivos alternativos, significativamente menos tóxicos y que integran al hombre en el cuidado de la anticoncepción. Tal como lo demuestra Preciado en un breve análisis historiográfico de las mutaciones de la píldora, desde su surgimiento hasta sus versiones más recientes y sofisticadas, esta se proyectaría a largo plazo como un programa de producción cosmética de la feminidad acorde con los códigos estéticos con que se gestiona y evalúa mediáticamente el cuerpo femenino. 
[La píldora] aparece cada vez más como una terapia en el tratamiento del acné, del llamado hirsutismo (...) o el aumento del volumen y mejora de la forma del pecho. Se fabrican así nuevas píldoras (...) [que] prometen una disminución de la retención de líquidos y una pérdida de peso corporal. Asimismo, las terapias hormonales parecen seducir hoy a un público de consumidoras que desearía reducir la frecuencia y la intensidad de las reglas. Ya no se trataría tanto de una utilización contraceptiva (...), sino de gestión de los ciclos menstruales (2008: 143).

La subjetivación farmacopornográfica inducida a través de la píldora se encontraría paralelamente supeditada a la construcción de la noción de género, $\mathrm{y}$, por cierto, de sus patrones estéticos y conductuales, convertidos en dispositivo técnico visual y performativo de sexuación del cuerpo, difundido como punto de referencia, permanentemente actualizado, en los medios de comunicación y prácticamente todo espectáculo de la industria cultural. Así, por medio de la sintetización y consumo de la píldora inducimos artificial y unilateralmente los patrones de belleza positivos en los cuerpos identificados biopolíticamente como femeninos. De este modo, la píldora emerge como protocolo institucional de positivación de la realidad somática del cuerpo femenino. Así, el mal femenino a exorcizar técnicamente cobra la forma de los granos, el vello facial, la copa A y la gordura. Resulta llamativo el término panóptico comestible con el cual la autora designa la píldora y, a su vez, subraya la mutación de los instrumentos técnicos de gestión de la vida, cuyo foco de acción se sitúa ahora en la dimensión interna de los cuerpos: "la torre de vigilancia ha sido sustituida ahora por los ojos de la consumidora dócil de la píldora, que sin necesidad de mirada exterior, regula su propia administración siguiendo el calendario espacial propuesto por la plaqueta circular o rectangular" (2008: 35 ) en que son presentadas las píldoras anticonceptivas. En general, de la misma forma, todos hemos sucumbido frente a las promesas de libertad y soberanía sexual ofrecidas por la industria farmacéutica.

Con la sintetización del Viagra, molécula vasodilatadora capaz de provocar y mantener erecciones, y la testosterona, hormona esteroidea, biopolíticamente asignada al sexo masculino y asociada convencionalmente con el vigor y el deseo sexual, ocurriría un fenómeno de positivación del cuerpo identificado como masculino, equivalente al de las mujeres y la píldora. Con la producción y consumo de estas sustancias, la masculinidad deja de ser una condición natural inmanente, para pasar a ser dominio de la tecnociencia, poniendo al descubierto, asimismo, un desequilibrio político evidente: "mientras que el interés por los testículos y las hormonas masculinas está dirigido a virilizar y sexualizar a los hombres (...), los proyectos de investigación de las hormonas consideradas como femeninas buscan controlar la sexualidad de las mujeres y su capacidad de reproducción" (2008: 127). En el caso de los hombres, el foco de las medidas profilácticas se centra en la producción técnica de la soberanía sexual masculina, cuyo mal a exorcizar técnicamente radica, precisamente, en la pérdida de dicha soberanía, es decir, en la disfunción eréctil.

En un movimiento de naturalización de la subalternidad, este desequilibrio político, reforzado técnicamente y proyectado somáticamente de los cuerpos, mana de los códigos pornográficos normativos con que se representa la sexualidad y se gestiona el circuito productor de placer y plusvalía, excitación-frustración-excitación 
(Preciado 2008). El porno pone en representación el monopolio masculino del placer, tal como lo concibe Robert H. Rimmer, quien expone los códigos con que se rige la representación pornográfica del sexo heterosexual y que reproduce Roman Gubern en su libro La imagen pornográfica y otras perversiones ópticas (2005). En síntesis, es posible caracterizar la sexualidad del porno heterosexual como la de un hombre que, negándose a la penetración anal, hace visible su capacidad de hacer gozar a la mujer en tanto receptor de su esperma visiblemente lanzada sobre la superficie de su cuerpo; cuyo sexo pasivo siempre se mantiene abierto, lubricado y dispuesto para el goce. Las escenas se encuentran depuradas de emociones y debilidades intrínsecas de lo humano, asociadas a la decrepitud física, la vejez, la enfermedad, las excrecencias o el embarazo; presentándose, muchas veces, a los actores en locaciones elegantes y socialmente privilegiadas, o bien, en espacios potencialmente asociables con fantasías sexuales masculinas heterosexuales. En la reducción del sujeto a respuesta masturbatoria, en el control telecomandado de la subjetividad, se revela que el objetivo del porno y de toda producción cultural, audiovisual y farmacológica es la producción de una satisfacción frustrante sexopolitica, es decir, de la producción de un placer que resulta en el gobierno de los penes, los anos y las vaginas (2008). Así, las tecnologías de subjetivación, en tanto máquinas de producción ontológica, hacen que las performatividades normativas de género cristalizadas en el discurso pornográfico se inscriban como verdades biológicas inalterables; perpetuando, de este modo, la soberanía sexual de una masculinidad virilizada (positivada) por el Viagra y la pornografía, y la condición de prótesis masturbatoria, anal y/o vaginal, de una feminidad feminizada (positivada) por la píldora, la dieta y el ejercicio físico. Así, todos, sin distinción alguna, emergemos en este orden de cosas como subjetividades toxicopornográficas, es decir, "subjetividades que se definen por la sustancia (o sustancias) que domina sus metabolismos, por las prótesis cibernéticas a través de las que se vuelven agentes, por los tipos de deseos farmacopornográficos que orientan sus acciones" (2008: 33).

El barebaking, es decir, el sexo sin condón, fue considerado por la comunidad homosexual posterior a la irrupción de la pandemia de VIH, cuyo epicentro fue San Francisco, como una práctica de resistencia a los discursos médicos institucionales promotores de la desconfianza y del sexo seguro y aséptico. Preciado dedica una interesante columna de reciente publicación on line a un nuevo fármaco que promete acabar con los peligros de esta práctica: Truvada o PrEP (Profilaxis pre-exposición), aprobado por la FDA en el año 2012, se presenta como un condón químico que evita la seroconversión del individuo que lo consume en forma continua, a pesar de ser expuesto directamente al virus de VIH. Para Preciado (2015), PReP funcionaría como una máquina social, que -igual que la píldora y el Viagra- posibilita la construcción de la fantasía de una sexualidad masculina positivada, natural y totalmente soberana, no restringida por barreras físicas e higienizada de la tara social del VIH.

Si el barebacking (el sexo sin condón entre gays seropositivos) se pensó en los 90 como una suerte de terrorismo sexual, ahora el sexo seguro y responsable es el barebacking con Truvada. Farmacológicamente higiénico, sexualmente viril. El poder del fármaco reside en su capacidad para producir una sensación de autonomía y libertad sexual. Sin mediación visible, sin condón de látex, el cuerpo 
masculino penetrante obtiene la sensación de plena soberanía sexual, cuando en realidad cada una de sus gotas de esperma está mediada por complejas tecnologías farmacopornográficas (Preciado 2015: párrafo 4).

De este modo, comprobamos la hipótesis de Zizek, al verificar que Truvada constituye un eslabón más de la larga cadena de tecnologías de subjetivación dispuestas por el capitalismo para neutralizar, en este caso, la articulación de un movimiento micropolítico, en tentativa de singularización, que generó formas de resistencia concretas contra los discursos disciplinarios impulsores de una sexualidad aséptica, desprovista de negatividad: la mujer es a la gordura, lo que los hombres a la disfunción eréctil y los homosexuales al contagio del VIH. En los 70, Hocquenghem ya intuía este proceso de captura y neutralización del movimiento homosexual en las políticas identitarias, que ya se perfilaban en ese entonces, y a los que se reduce este problema hoy día: el casamiento y la adopción constituyen las dos políticas sociales a través de las que se produce la integración de los homosexuales a cierto modelo identitario uniforme e inofensivo. Truvada, paralelo a estas políticas, es un fármaco que emerge como una estrategia de higienización invisible y cómoda, como un recurso farmacológico al servicio de la edipización homosexual, es decir, de la gestión y reducción del deseo homosexual al territorio de lo familiar, limando, de este modo, el potencial subversivo de todo un movimiento que prometía redefinir las convenciones sociales normativas y naturalizadoras del sexo y la sexualidad. Basta con analizar superficialmente las propuestas teóricas de Hocquenghem en El deseo homosexual (1972), producidas durante su período de militancia en la FHAR (Front homosexueld'actionrevolutionna ir), para comprender que ya no queda nada de dicho movimiento. Cuando Perlongher entregó su diagnóstico acerca del estado de la cuestión homosexual en el ensayo $\mathrm{La}$ muerte de la homosexualidad, publicado en 1991, es decir, un año antes de su muerte, intuyó las implicancias políticas del VIH: "Con el Sida se va dando, sobre todo en el terreno homosexual (...) otra vuelta de tuerca del propio dispositivo de sexualidad, no en el sentido de la castidad, sino en el sentido de recomendar, a través del progresismo médico, la práctica de una sexualidad limpia, sin riesgos, desinfectada y transparente" (2008: 87-88). De ahí que Perlongher considere el VIH como una reactualización de la problemática del culo que Truvada, precisamente, solucionaría de forma definitiva: "el fantasma del Sida habrá, en los días de hoy, de actualizar el miedo ancestral a la mixtura mucosa, al contacto del semen con la mierda, de la perla gomosa de la vida con la abyección fecal" (2008: 37). Nuevamente todo se reduce a la yuxtaposición de un doble movimiento: a la neutralización de la otredad inmunológicamente efectiva (homosexuales locas, seropositivos, practicantes del barebaking) por medio de la producción de una inmunidad artificial (Truvada), subjetivadora en serie de cuerpos dóciles, inofensivo y positivados técnicamente (homosexualidad edípica).

\section{Consideraciones finales}

Las tres tecnologías de subjetivación farmacopornográfica estudiadas constituyen un corpus representativo de casos que ponen en evidencia la presencia de una tendencia 
general a la aplicación de medidas profilácticas como efecto de la gubenamentalidad biopolítica, al nivel de la gestión de los fenómenos masivos de población y en torno a ciertas prácticas corporales que comportan una negatividad a alterizar técnicamente: acercamos al otro volviéndolo transparente, solo bajo la condición de que emerja en el territorio de lo visible como otredad positivada técnicamente. A la espumización (Sloterdijk) y la erosión de las distancias (Han y Virilio), le suceden como condicionante transversal de la cohabitación espacial y temporal, medidas profilácticas orientadas a la anulación de la negatividad de los cuerpos. A la profilaxis de la gordura, la disfunción eréctil y la homosexualidad, probablemente en el futuro le sucederán la muerte y, junto con ella, todas las limitaciones intrínsecas de lo humano, hasta que podamos prescindir de nuestro cuerpo material y descargar nuestras mentes en el espacio virtual. Llegado a este punto, podemos realizar algunas preguntas. En la subjetivación farmacopornográfica, ¿qué es primero, el sujeto o las tecnologías que lo constituyen como tal? ¿Acaso hemos llegado a un momento de la historia donde la subjetividad ha sido completamente cooptada y reemplazada por la estructura? Un desequilibrio, quizás primigenio, entre la naturaleza y la cultura se esconde tras la idea de la muerte del hombre que, en este contexto, parece la más obvia de las conclusiones. Si hemos explicado ampliamente el modo en que los cuerpos se han tornado dóciles a las nuevas tecnologías de subjetivación, habría que concentrarnos ahora en la otra cara de este problema, es decir, en las posibilidades de subversión y las dificultades específicas que esta empresa supone en el contexto de las espumas sociales.

\section{Referencias bibliográficas}

Alain, Corbin, Courtine, Jean y George Vigarello (2006), Historia del cuerpo. Volumen 3. Las mutaciones de la mirada. Madrid: Taurus.

Arcand, Bernard (1991), Antropología de la pornografía. El Jaguar y el Oso Hormiguero. Buenos Aires: Nueva Visión.

Baudrillard, Jean (2008), El pacto de lucidez o la inteligencia del mal. Buenos Aires: Amorrortu.

(2000), El crimen perfecto. Barcelona: Anagrama.

Corbin A., J. J. Courtine y G. Vigarello (2006), Historia del Cuerpo III. Las mutaciones de la mirada. El siglo XX. Madrid: Editorial Taurus.

Deleuze, Gilles (2008), Dos regímenes de locos. Textos y entrevistas(1975-1995). Valencia: Pre-textos.

(1991), Postdata sobre las sociedades de control. En Ferrer, Christian (Comp.) El lenguaje literario. Disponible en: http://bit.ly/1SfdF0C

Esposito, Roberto (2006), Bios. Biopolitica y filosofia. Buenos Aires: Amorrortu.

Foucault, Michel (2016), La vida de los hombres infames. Santiago: Hiparquía Ediciones.

(2009), Historia de la sexualidad. La voluntad de saber. México: Siglo XXI. 
(2003), Vigilar y Castigar. Nacimiento de la prisión. Buenos Aires: Siglo XXI.

Guattari, Felix y Suely Rolnik (2006), Cartografias del deseo. Madrid: Traficante de sueños.

Gubern, Roman (2005), La imagen pornográfica y otras perversiones ópticas. Barcelona: Anagrama.

Han, Byung Chun (2014), La agonía del Eros. Barcelona: Herder. (2012), La sociedad del cansancio. Barcelona: Herder.

Hardt, Michael y Antonio Negri (2000), Imperio. Cambridge: Harvard University Press.

Hocquenguem, Guy (2009), El deseo homosexual. España: Melusina.

Perlongher, Néstor (2008), Prosa plebeya: Ensayos 1980-1992. Buenos Aires: Colihue.

Preciado, Beatriz (2015), Condones químicos. 22/08/16, de Parole de Queer. Sitio web: http://bit.ly/2bpENNr (2008), Testo yonki. Madrid: Espasa Calpe. (2010), Pornotopia. Barcelona: Anagrama.

Sloterdijk, Peter (2010), En el mundo interior del capital. Para una teoría filosófica de la globalización. Madrid: Siruela. (2006), Esferas III. Madrid: Siruela. (2003), Esferas I. Madrid. Siruela.

(2003), Experimentos con uno mismo. Una conversación con Carlos Oliviera. Valencia: Pre-Textos.

Virilio, Paul (1999), La bomba informática. Madrid: Cátedra. (1997), El cibermundo, la política de lo peor. Madrid: Cátedra.

Virno, Paolo (2003), Gramática de la multitud. Para un análisis de las formas de vida contemporáneas. Madrid: Traficante de sueños.

Zizek, Slavoj (2009), Sobre la violencia. Seis reflexiones marginales. Barcelona: Paidós. (2008), En defensa de la intolerancia. Madrid: Sequitur. 